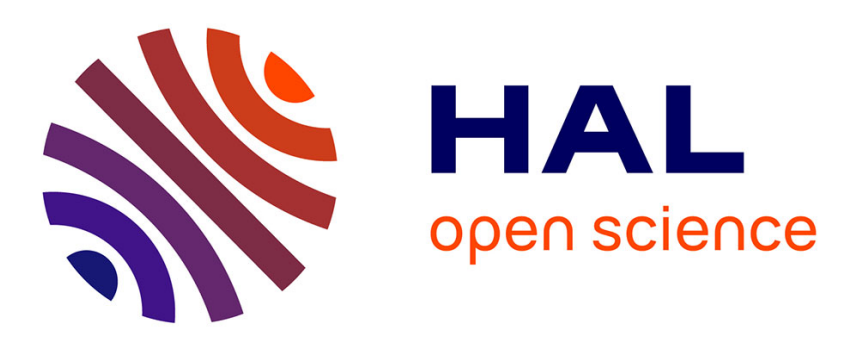

\title{
Effect of unstable crack growth on mode II interlaminar fracture toughness of a thermoplastic PEEK composite
}

Pablo Garcia Perez, Christophe Bouvet, Ameur Chettah, Frédéric Dau, Ludovic Ballère, Patrick Peres

\section{- To cite this version:}

Pablo Garcia Perez, Christophe Bouvet, Ameur Chettah, Frédéric Dau, Ludovic Ballère, et al.. Effect of unstable crack growth on mode II interlaminar fracture toughness of a thermoplastic PEEK composite. Engineering Fracture Mechanics, 2019, 205, pp.486-497. 10.1016/j.engfracmech.2018.11.022 . hal-02009423

\section{HAL Id: hal-02009423 \\ https://hal.science/hal-02009423}

Submitted on 6 Feb 2019

HAL is a multi-disciplinary open access archive for the deposit and dissemination of scientific research documents, whether they are published or not. The documents may come from teaching and research institutions in France or abroad, or from public or private research centers.
L'archive ouverte pluridisciplinaire HAL, est destinée au dépôt et à la diffusion de documents scientifiques de niveau recherche, publiés ou non, émanant des établissements d'enseignement et de recherche français ou étrangers, des laboratoires publics ou privés. 


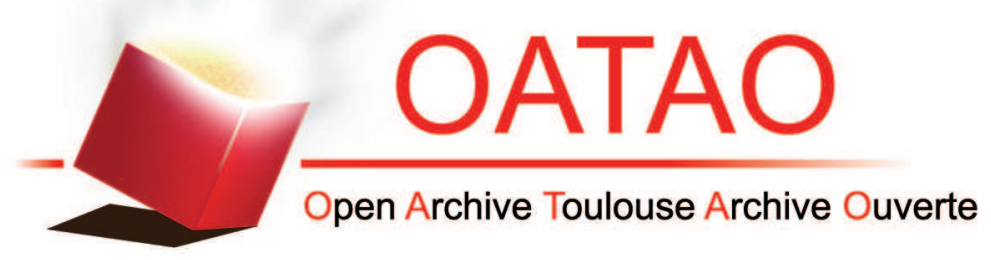

\section{Open Archive Toulouse Archive Ouverte (OATAO)}

OATAO is an open access repository that collects the work of some Toulouse researchers and makes it freely available over the web where possible.

This is an author's version published in: https://oatao.univ-toulouse.fr/21849

Official URL: https://doi.org/10.1016/j.engfracmech.2018.11.022

\section{To cite this version :}

Garcia Perez, Pablo and Bouvet, Christophe and Chettah, Ameur and Dau, Frédéric and Ballère, Ludovic and Peres, Patrick Effect of unstable crack growth on mode II interlaminar fracture toughness of a thermoplastic PEEK composite. (2019) Engineering Fracture Mechanics, 205. 486-497. ISSN 0013-7944

Any correspondence concerning this service should be sent to the repository administrator: tech-oatao@listes-diff.inp-toulouse.fr 


\title{
Effect of unstable crack growth on mode II interlaminar fracture toughness of a thermoplastic PEEK composite
}

\author{
P. Garcia Perez ${ }^{\mathrm{a}}$, C. Bouvet ${ }^{\mathrm{b}, *}$, A. Chettah ${ }^{\mathrm{c}}$, F. Dau ${ }^{\mathrm{a}}$, L. Ballere ${ }^{\mathrm{d}}$, P. Pérès ${ }^{\mathrm{d}}$ \\ ${ }^{\text {a }}$ Arts et Métiers ParisTech, I2M, Talence, France \\ ${ }^{\mathrm{b}}$ Université de Toulouse, ISAE-SUPAERO, ICA, Toulouse, France \\ ${ }^{\mathrm{c}}$ Université Bourgogne Franche-Comté, ISAT, DRIVE, France \\ ${ }^{\mathrm{d}}$ Ariane Group, Saint-Médard-en-Jalles, France
}

\section{Keywords:}

Unstable crack growth

Delamination

Polymer matrix composites

\begin{abstract}
A B S T R A C T
An end notched flexure (ENF) test was used to study the effect of growth stability on mode II interlaminar fracture toughness $\left(\mathrm{G}_{\mathrm{IIC}}\right.$ ) of a carbon/PEEK composite. The instability of the ENF test was used to induce both stable and unstable crack growth with a static loading. Two techniques were used to evaluate mode II fracture toughness: the traditional compliance method and the infra-red thermography technique. The compliance technique has the advantage of being simple and it has already been confirmed for standard tests. Nevertheless its results may be inaccurate for unstable crack growth propagation. The infra-red thermography technique enables fracture toughness to be accurately measured for non-standard tests in which the crack growth may be unstable.

Both methods are complementary and this study came to the conclusion that $\mathrm{G}_{\text {IIC }}$ is sensitive to crack growth velocity. Fracture toughness showed a low value for crack growth start and unstable propagation, and a high value for stable crack growth. The transition between a ductile fracture mode (for low crack growth velocity) and a brittle fracture mode (for high crack growth velocity) explained the important variability in $\mathrm{G}_{\mathrm{IIC}}$ values.
\end{abstract}

\section{Introduction}

High performance thermoplastics are increasingly considered in composite structures mainly for damage tolerance reasons. These materials are actually considered more damage tolerant than thermoset based composite materials [1,2]. Semi crystalline thermo plastic resins offer a number of advantages over conventional thermoset resins (such as epoxies): a high degree of chemical resistance, excellent damage and impact resistance and they may be used over a wide range of temperatures.

From a general standpoint, it appears from the literature that thermoplastic based composites display a better resistance to impact damage than epoxy based composites. Among the properties governing the impact behavior of laminated composites, mode I and mode II critical energy release rates (ERR), $\mathrm{G}_{\mathrm{IC}}$ and $\mathrm{G}_{\mathrm{IIC}}$, are of the utmost importance [2 8].

Despite the high difference between the critical ERR of thermoplastic and thermoset composite materials, the gain on impact damage tolerance is not as great as expected [7,8]. Mode I ERR is about $4 \mathrm{~N} / \mathrm{mm}$ for pure PEEK resin and about $0.5 \mathrm{~N} / \mathrm{mm}$ for pure epoxy resin [7]. However, the fracture behavior of composite material is weaker. For example, carbon/PEEK fracture toughness (FT) is about $1.5 \mathrm{~N} / \mathrm{mm}$ in mode I and $2 \mathrm{~N} / \mathrm{mm}$ in mode II [9 12], whereas carbon/epoxy T700/M21 FT is about $0.5 \mathrm{~N} / \mathrm{mm}$ in mode I and

\footnotetext{
* Corresponding author.

E-mail address: Christophe.bouvet@isae.fr (C. Bouvet).
} 


\section{Nomenclature}

Latin variables

a crack length

B sample width

C compliance or specific heat capacity

$c_{0} \quad$ speed of a longitudinal wave

$\mathrm{dW}_{\text {diss }}$ intrinsic dissipation

$\mathrm{dW}_{\text {irrev }}$ irreversible energy

$\mathrm{E}_{1} \quad$ Young modulus in the fiber direction

F force

$\mathrm{G} \quad$ energy release rate

$\mathrm{G}_{\text {IIC }}$ mode II interlaminar fracture toughness

I area moment of inertia of the beam

$\mathrm{L} \quad$ beam length between supports

$s_{\text {the }} \quad$ thermo mechanical coupling

u displacement

Greek variables $\dot{\varepsilon}$

$\phi_{\text {int }} \quad$ intrinsic dissipation

$\phi_{\text {irrev }} \quad$ irreversible dissipation

$\phi_{\text {stored }}$ stored energy

$\theta \quad$ temperature variation

$\rho \quad$ mass density

$\Omega_{\text {fis }} \quad$ volume containing the crack

Acronyms

ENF end notched flexure test

ELS end loaded split test

ERR critical energy release rates

FRMM fixed ratio mixed mode test

FT fracture toughness

IRT infrared thermography

$\mathrm{k}_{\mathrm{ll}}\left(\mathrm{k}_{\mathrm{tt}}, \mathrm{k}_{\mathrm{zz}}\right)$ conductivity in $\mathrm{l}(\mathrm{t}, \mathrm{z})$ direction

LVDT linear variable differential transformer

PEEK polyether ether ketone

Taylor Quinney coefficient

$1.6 \mathrm{~N} / \mathrm{mm}$ in mode II $[13,14]$. Therefore fracture toughness is currently higher for thermoplastic than for thermoset, but the dif ference is less important for composite than for pure resin. Moreover, impact damage tolerance is mostly driven by mode II FT $[15,16]$, and the difference between thermoset and thermoplastic composite fracture toughness is lower in mode II than in mode I.

Another important point dealing with damage tolerance of thermoplastic composites is the rate sensitivity of the crack growth. In fact, some authors show that critical ERR changes with the velocity of the crack growth. It is particularly the case for interlaminar shear fracture [6,9 11,17]. Friedrich et al. [9 11] performed End Notched Flexure (ENF) tests at room temperature over a range of crosshead speeds from $4.2 \times 10^{-6}$ to $9.2 \times 10^{-2} \mathrm{~m} / \mathrm{s}$ and showed that $\mathrm{G}_{\text {IIC }}$ of APC 2 PEEK resin decreases from 1.9 to $0.4 \mathrm{~N} / \mathrm{mm}$ when crack growth velocity increases (Fig. 1a). They explained that the APC 2 material exhibits ductile crack growth at low rates (Fig. 2a) and brittle crack growth at high rates (Fig. 2b).

Blackman et al. [18] used an End Loaded Split (ELS) test and a Fixed Ratio Mixed Mode (FRMM) test to evaluate carbon/PEEK fracture toughness under high rates in mixed mode I/II and mode II loadings. They showed that $\mathrm{G}_{\text {IIC }}$ decreases from $2.5 \mathrm{~N} / \mathrm{mm}$ at the slowest test rate (of about $10^{-4} \mathrm{~m} / \mathrm{s}$ ), to $2.2 \mathrm{~N} / \mathrm{mm}$ at the highest test rate (of about $3 \mathrm{~m} / \mathrm{s}$ ). Contrary to these results, Berger and Cantwell [19] found that AS4/carbon fiber reinforced PEEK interlaminar fracture toughness increased as the crosshead displacement rate increased. They carried out a double ENF test and their study shows that $\mathrm{G}_{\text {IIC }}$ increases from 2.2 to $2.7 \mathrm{~N} / \mathrm{mm}$ for a crosshead displacement rate increasing from $1.7 \times 10^{-6}$ to $8.3 \times 10^{3} \mathrm{~m} / \mathrm{s}$. They concluded that mode II interlaminar fracture toughness is strongly influenced by the yield stress of thermoplastic resin. In their study, the temperature influence (from 20 to $150{ }^{\circ} \mathrm{C}$ ) was also studied. The authors concluded that increasing the test temperature has the same effect as decreasing the loading rate; these two phenomena induce similar reductions in the value of $\mathrm{G}_{\text {IIC. }}$. The authors compared the $25 \%$ increase in $\mathrm{G}_{\text {IIC }}$ (at $20{ }^{\circ} \mathrm{C}$ ) with the $25 \%$ increase in yield stress found by Béguelin et al. [20]. They concluded that the rate sensitivity of the mode II interlaminar fracture
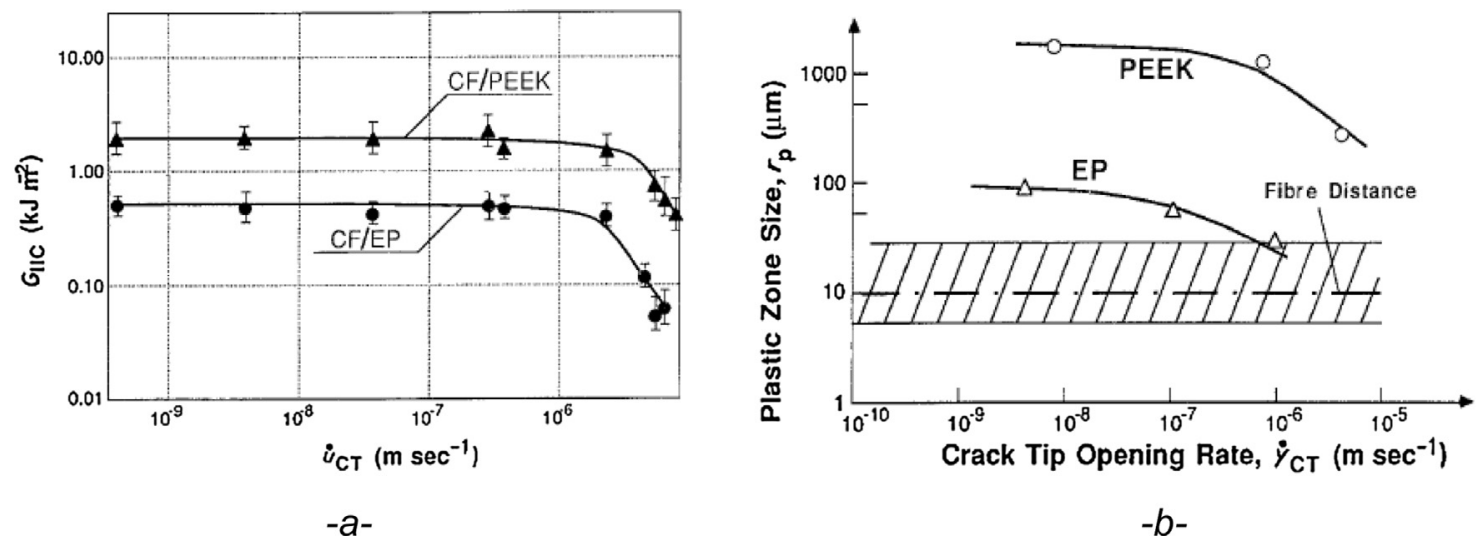

Fig. 1. Effect of the crack growth speed on mode II fracture toughness (a) and plastic zone size (b) [9]. 


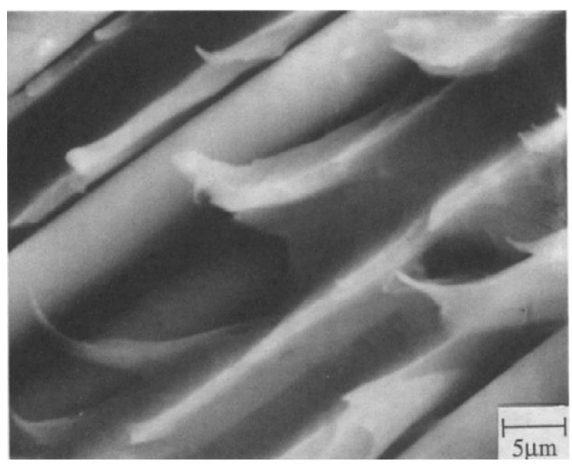

$-a-$

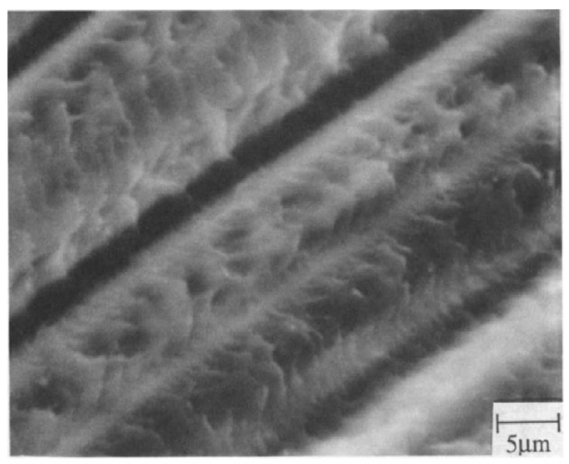

$-b-$

Fig. 2. Mode II ductile behavior (a) and mode II brittle behavior (b) [10].

energy is related to the rate dependent characteristics of the PEEK matrix. At the same time, the results showed that the damage zone length increases from about 1 to $1.3 \mathrm{~mm}$ as the loading rate increases from $1.7 \times 10^{-6}$ to $8.3 \times 10^{3} \mathrm{~m} / \mathrm{s}$ [19]. This result is con tradictory with Friedrich et al.'s work [9 11 ] who showed that the damage zone size decreased as the loading rate increased (Fig. $1 \mathrm{~b}$ ).

The goal of this article is to contribute to this complex discussion on the effect of the rate on the $\mathrm{G}_{\text {IIC }}$ value. Most of the work found in the literature studies the effect of the loading rate on $\mathrm{G}_{\text {IIC }}$ because it can be easily evaluated. The authors of this article assert that the loading rate is not the appropriate parameter to study fracture toughness variability but crack growth velocity is, even though it is more difficult to assess. In fact, the same loading rate can induce very different crack growth speeds depending on the boundary conditions. This fact could partly explain the difference in $\mathrm{G}_{\text {IIC }}$ values observed in the literature. For example, the ENF test can induce stable (low velocity crack growth) or unstable propagations (high velocity crack growth) [14,21 23]. This instability is often con sidered a disadvantage and the standard proposes a configuration intended to avoid it [21,22]. But if the goal is to induce fast crack growth, this instability is very interesting and enables dynamic crack growth to be assessed by performing a static test.

In this project, several ENF tests were carried out in order to compare stable and unstable crack growth. An ultra high speed camera was also used to precisely measure crack growth velocity in an unstable ENF test. Then, two experimental techniques were used to study the effect of crack growth instability on the mode II fracture toughness value.

\section{ENF test}

The composite material examined in this study is an unidirectional prepreg laminate with IM7 carbon fiber and PEEK resin. The Young modulus in the fiber direction, $\mathrm{E}_{\mathrm{l}}$, is shown in Table 1 , where $\mathrm{l}$ is the longitudinal direction, $\mathrm{t}$ the transverse direction and $\mathrm{z}$ the out of plane direction. Plates were manufactured with draping sequence $[0]_{32}$. The first samples $\left(\mathrm{ENF}_{1}\right.$ to $\left.\mathrm{ENF}_{5}\right) \mathrm{were} \mathrm{made}_{\mathrm{d}} \mathrm{with}_{\mathrm{i}} \mathrm{plies}$ of $0.137 \mathrm{~mm}$ thickness for a total thickness, $\mathrm{h}$, of $4.4 \mathrm{~mm}$. They were used to understand the behavior of the specimen and to observe stable and unstable propagation using an infrared camera. The $\mathrm{ENF}_{6}$ to $\mathrm{ENF}_{9}$ samples were made from a different ply batch. The ply thickness was $0.145 \mathrm{~mm}$ for a total thickness of $4.65 \mathrm{~mm}$. These tests were filmed with an ultrahigh speed camera to evaluate crack growth velocity and with an infrared camera to determine $\mathrm{G}_{\mathrm{IIC}}$ values.

The samples were prepared with a teflon film inserted at mid thickness in order to initiate the crack. Afterwards, a box cutter was used to initiate the crack from the Teflon film, which allowed for different initial crack lengths. Then ENF samples were cut to a length of $250 \mathrm{~mm}$ and a width of $20 \mathrm{~mm}$. The geometry of the ENF test is shown in Fig. 3: the plate was simply supported on two $10 \mathrm{~mm}$ diameter cylinders and force was imposed using a $10 \mathrm{~mm}$ diameter cylinder. The velocity of the central cylinder was imposed at $0.028 \mathrm{~mm} / \mathrm{s}$. The force, $\mathrm{F}$, was measured during tests using the machine cell force and the displacement, $\mathrm{u}$, was measured using a LVDT sensor placed under the sample.

The first test, $\mathrm{ENF}_{1}$ sample, failed under the loading point. This failure was due to fiber failure just under the cylinder, probably due to high compression and shear stress concentration in this zone. In order to avoid this premature failure, a rubber piece of about $2 \mathrm{~mm}$ thickness, was set under the upper cylinder (Fig. 3). It spread the applied load over a wider specimen surface without disturbing the force measurement. As a result, the stress state in the specimen was more uniform. With this rubber piece, no other failure was observed under the force cylinder.

Table 1

Mechanical and thermal properties of carbon/PEEK UD ply [41-43].

\begin{tabular}{ll}
\hline Young's modulus in fiber direction, $\mathrm{E}_{\mathrm{l}}$ & $155 \mathrm{GPa}$ \\
Thermal conductivity in fiber direction, $\mathrm{k}_{\mathrm{ll}}$ & $5.4 \mathrm{~W} \cdot \mathrm{m}^{1} \cdot \mathrm{K}^{1}$ \\
Thermal conductivity in transverse direction, $\mathrm{k}_{\mathrm{tt}}$ and $\mathrm{k}_{\mathrm{zz}}$ & $0.25 \mathrm{~W} \cdot \mathrm{m}^{1} \cdot \mathrm{K}^{1}$ \\
Specific heat, C & $859 \mathrm{~J} \cdot \mathrm{kg}^{1} \cdot \mathrm{K}^{1}$ \\
Density, $\rho$ & $1610 \mathrm{~kg} \cdot \mathrm{m}^{3}$ \\
\hline
\end{tabular}




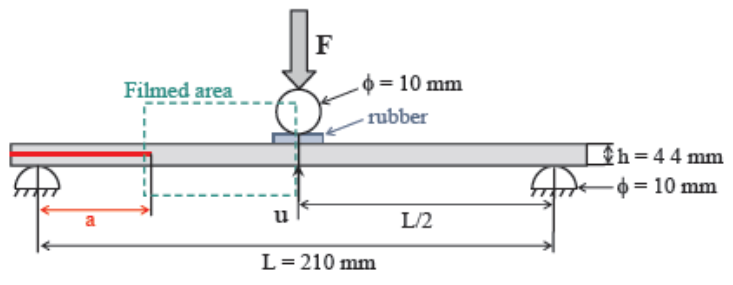

Fig. 3. ENF test setup.

\subsection{Force displacement curve}

In Fig. 4, evolution of force is plotted against displacement for an unstable ENF test $\left(\mathrm{ENF}_{2}\right)$ and a stable ENF test $\left(\mathrm{ENF}_{3}\right)$. $\mathrm{Crack}$ length is also plotted from the start of the growth. Crack length evolution was determined using photos of the sample, which were painted white in order to facilitate crack detection. Initial stiffness of the sample was obtained by measuring the initial crack length. $\mathrm{ENF}_{2}$ had a shorter initial crack than $\mathrm{ENF}_{3}$ and so its stiffness is higher. After the crack growth started, a small decrease in the beam stiffness was observed up to the maximum force (Fig. 4). This phenomenon is typical of the R curve effect. For ENF tests, the shorter the initial crack, the higher the maximum force [21 23]. Once the force reached maximum, sudden crack growth and load drop were observed. From this point of maximum force, the crack growth is stable for $\mathrm{ENF}_{3}$ and clearly unstable for $\mathrm{ENF}_{2}$ as we can see in the crack length in the Fig. 4.

\subsection{Damage propagation observation using infrared camera}

For the $\mathrm{ENF}_{4}$ and $\mathrm{ENF}_{5}$ samples an infrared camera was used to track damage evolution (Fig. 5). Both tests were operated at room temperature $(\approx 293 \mathrm{~K})$. An infrared camera (FLIR SC700 MW) was used to monitor the thermal response during the tests. The infrared camera has a maximum resolution of $320 \times 256$ pixels $^{2}$ and a thermal resolution of $0.025 \mathrm{~K}$ for relative temperature measurement. The spatial resolution (pixel size) determined by the focal distance is set at $0.16 \mathrm{~mm}$ (maximum magnification of the lens). Thermal images were recorded at a frequency of $50 \mathrm{~Hz}$. In order to avoid thermal perturbation from the external environment, the specimens were both enclosed in a black painted box covered with a black opaque fabric outside. The filmed area (Fig. 3) was between the central cylinder and the initial crack, at that point about $51 \mathrm{~mm}$ long ( 320 pixels multiplied by $0.16 \mathrm{~mm} / \mathrm{pixel}$ ). In Fig. 5 , the sample, central cylinder and rubber are shown before loading.

The crack growth for the ENF 5 test is shown in Fig. 6. The stable crack growth, before maximum force (Fig. 4), is difficult to see (frame 3847). In fact, with low crack growth velocity, heat energy has time to dissipate by conduction, reducing the rise in tem perature. Once the maximum force is reached, unstable propagation takes place (frames 3859 3862). Contrary to stable propagation, when crack growth is very fast, heat energy does not have time to dissipate by conduction, increasing the rise in temperature and facilitating the observation of the crack tip evolution. The high load drop in Fig. 4 corresponds approximately to frame 3861 ( $0.002 \mathrm{~s}$ separates two consecutive frames).

Crack growth is a very fast phenomenon, but once the crack propagates, the conduction of the heat energy dissipated by the crack is a slow phenomenon. Thermal conductivities are relatively low (Table 1) and the heat conduction lasts a few seconds. In order to observe this heat conduction, the temperature of a line crossing the crack (the vertical black line plotted in frame 3862 in Fig. 6) is plotted in Fig. 7. Heat conduction lasts a few frames and 20 frames (about $0.04 \mathrm{~s}$ ) after the crack crossing, temperature is almost

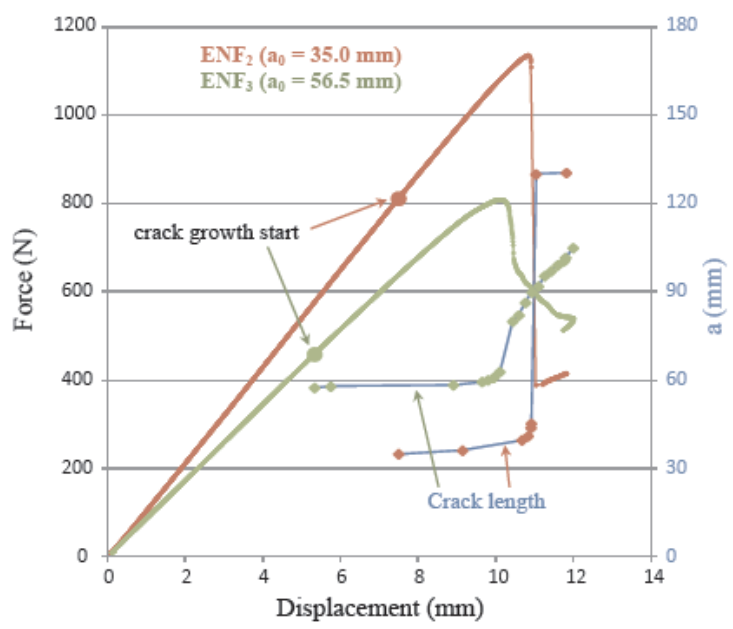

Fig. 4. Curves of force and crack length versus displacement of the ENF tests 2 and 3. 


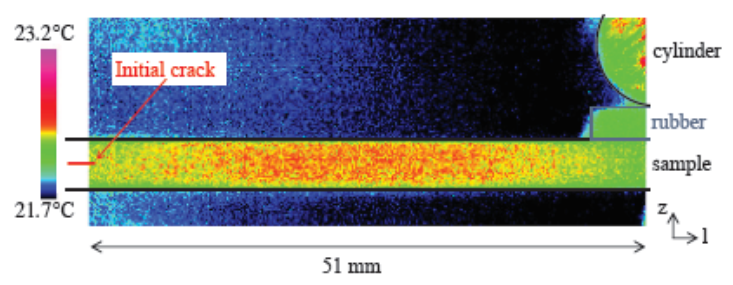

Fig. 5. Temperature field at the start of the ENF test.

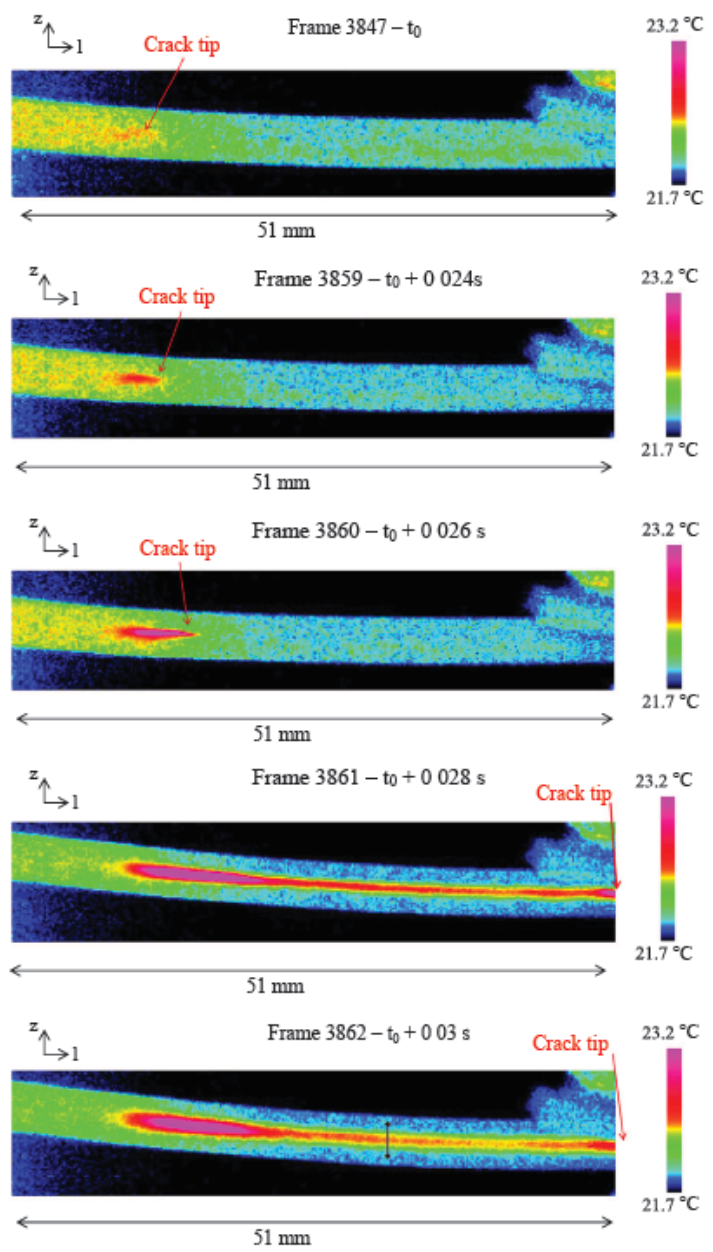

Fig. 6. Temperature field during the $\mathrm{ENF}_{5}$ test $(0.002 \mathrm{~s}$ separates 2 consecutive frames).

constant along the line. Mean temperature increases slightly due to the heat dissipated by the crack.

Notably, even if the thermal conductivity is higher in the longitudinal direction (i.e. almost horizontal direction in Fig. 6), heat conduction is mainly directed in the out of plane direction, z. Indeed, the temperature gradient is almost zero in the longitudinal direction (as well as in the transverse direction), because the phenomenon is translation invariant along the longitudinal (as well as transverse) direction. This phenomenon can be verified by plotting temperature changes for different lines, in the $\mathrm{z}$ direction, crossing the crack; the curves are all similar.

\subsection{Crack growth velocity for unstable propagation}

The $\mathrm{ENF}_{6}$ to $\mathrm{ENF}_{9}$ tests were recorded using an ultra high speed camera (Photron AS5) at a frequency of $105 \mathrm{kHz}$ making it possible to measure the evolution of the crack tip (Fig. 8). In order to better assess the propagation, two samples (ENF 6 and ENF $_{7}$ ) were treated with crack detection developer spray. During unstable propagation, a significant vibratory movement induced the detachment of powder particles that form a barrier between the camera and the sample. Therefore, the crack tip could not be properly 


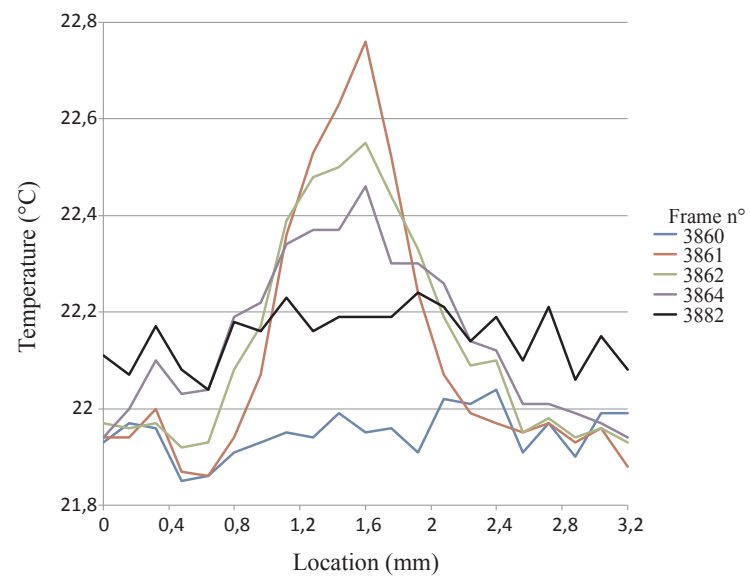

Fig. 7. Evolution of the temperature versus location for different time for the path defined Fig. 6 .

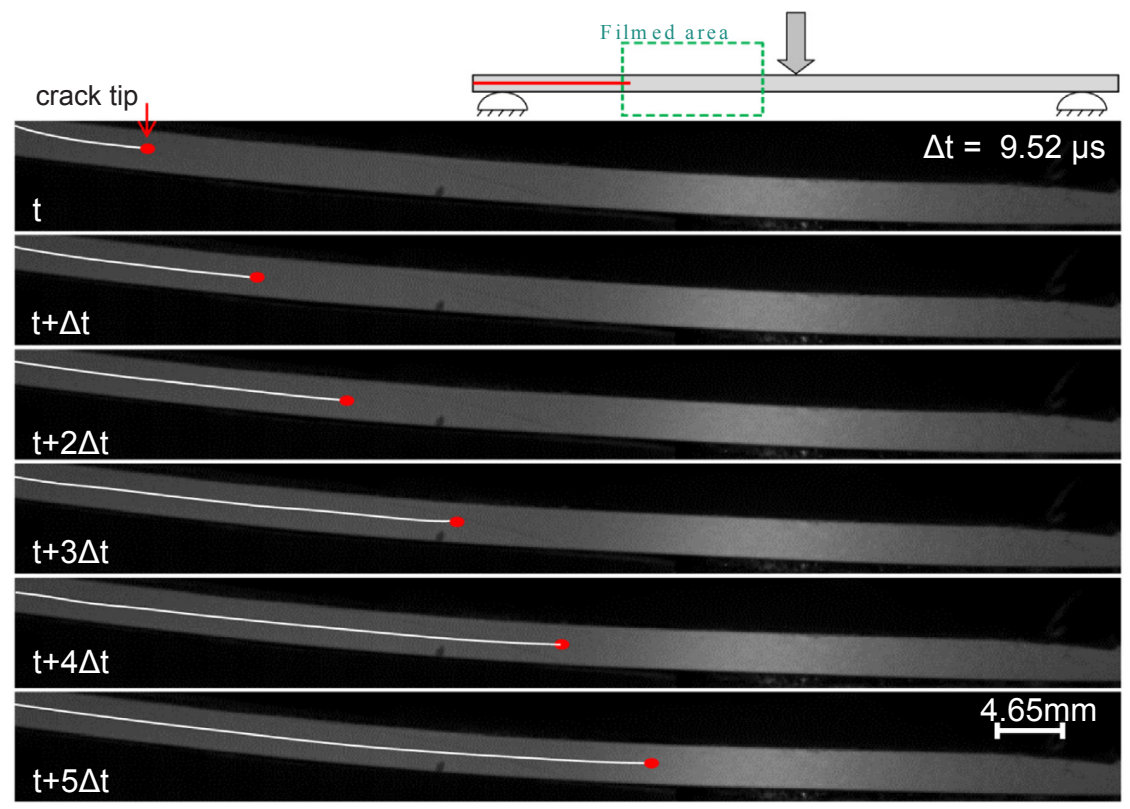

Fig. 8. Crack growth evolution during $\mathrm{ENF}_{8}$.

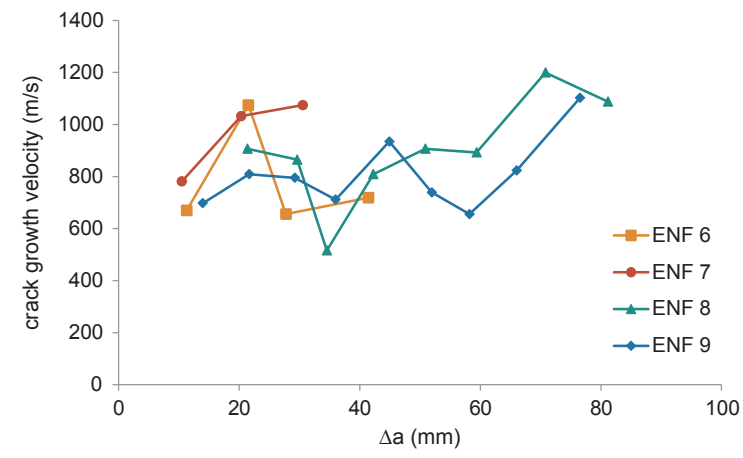

Fig. 9. Crack growth velocity during ENF tests. 
monitored for these samples so $\mathrm{ENF}_{8}$ and $\mathrm{ENF}_{9}$ samples were painted white so that crack propagation could be fully observed. The crack propagation mean velocity of each test varied from $807 \mathrm{~m} \cdot \mathrm{s}^{-1}$ to $962 \mathrm{~m} \cdot \mathrm{s}^{-1}$ with a maximum peak of $1200 \mathrm{~m} \cdot \mathrm{s}^{-1}$, Fig. 9 . Stroh et al. [24] shows that, in some specific configurations, crack growth velocity tends to the velocity of a perturbation travelling along a free surface. The maximum velocity is set by the Rayleigh waves speed [25] and can be estimated by $0.2-0.4 \times c_{0}$, with $c_{0}$ being the speed of a longitudinal wave $\left(c_{0}=\sqrt{E / \rho}\right)$ [26]. This estimation shows that the maximum crack growth velocity in our material varies from $1930 \mathrm{~m} \cdot \mathrm{s}^{-1}$ to $3860 \mathrm{~m} \cdot \mathrm{s}^{-1}$. Since the velocity of the ENF delamination is as high as $1200 \mathrm{~m} \cdot \mathrm{s}^{-1}$, it is proven that an ENF static loading can induce fast damage propagation if an instability condition is reached.

\section{Determination of $\mathrm{G}_{\mathrm{IIC}}$}

\subsection{Beam theory}

By applying classical beam theory, it is simple to study ENF test crack growth in the framework of linear elastic fracture me chanics [21 23]. If the structure behavior is assumed linear elastic, the energy release rate, $\mathrm{G}$, can be expressed by:

$$
G=\frac{F^{2}}{2 B} \frac{d C}{d a} \text { and } C=\frac{u}{F}
$$

where $\mathrm{B}$ is the sample width, $\mathrm{F}$ is the force, $\mathrm{a}$ is the crack length, $\mathrm{C}$ is the compliance and $\mathrm{u}$ is the displacement. Then crack growth is obtained when $\mathrm{G}$ equals the critical ERR in mode II, $\mathrm{G}_{\text {IIC }}$. If $\mathrm{G}_{\mathrm{IIC}}$ is assumed constant, the condition of crack growth stability allows for the expression of the displacement versus force using the beam theory [21 23]:

$$
\begin{aligned}
& \text { If } 0 \leq a \leq L / 2 \text { then } u=\frac{F L^{3}}{384 E I}+\frac{16}{F^{2}} \sqrt{E_{l} I}\left(\frac{B G_{I I C}}{3}\right)^{3 / 2} \\
& \text { If } \frac{L}{2} \leq a \leq L \quad \text { then } u=\frac{F L^{3}}{96 E I}-\frac{16}{F^{2}} \sqrt{E_{l} I}\left(\frac{B G_{I I}}{3}\right)^{3 / 2}
\end{aligned}
$$

where $\mathrm{L}$ is the beam length between boundary conditions (Fig. 3) and I is the area moment of inertia of the beam $\left(\mathrm{I}=\mathrm{Bh}^{3} / 12\right)$. These curves are plotted in Fig. 10 for two values of $\mathrm{G}_{\text {IIC. }}$. Higher values of $\mathrm{G}_{\text {IIC }}$ mean that more energy is needed to obtain crack propagation and so the force should also be higher. In this figure, the elastic behavior of the sample $(\mathrm{F}=\mathrm{u} / \mathrm{C})$, using the beam theory, is also plotted for $\mathrm{a}=0$ and $\mathrm{a}=\mathrm{L} / 2$ (the smaller the crack, the higher the stiffness):

$$
\begin{aligned}
& \text { If } 0 \leq a \leq L / 2 \text { then } C=\frac{L^{3}+12 a^{3}}{384 E I} \\
& \text { If } \frac{L}{2} \leq a \leq L \quad \text { then } C=\frac{L^{3}-3(L-a)^{3}}{96 E I}
\end{aligned}
$$

If the ENF is controlled with displacement, which is the case of the experimental tests presented here, the stability condition of the crack growth is reached for a $>0.347 \mathrm{~L}$ (Fig. 4). In reality, the problem is more complex, because $\mathrm{G}_{\mathrm{IIC}}$ is not constant, and the $\mathrm{R}$

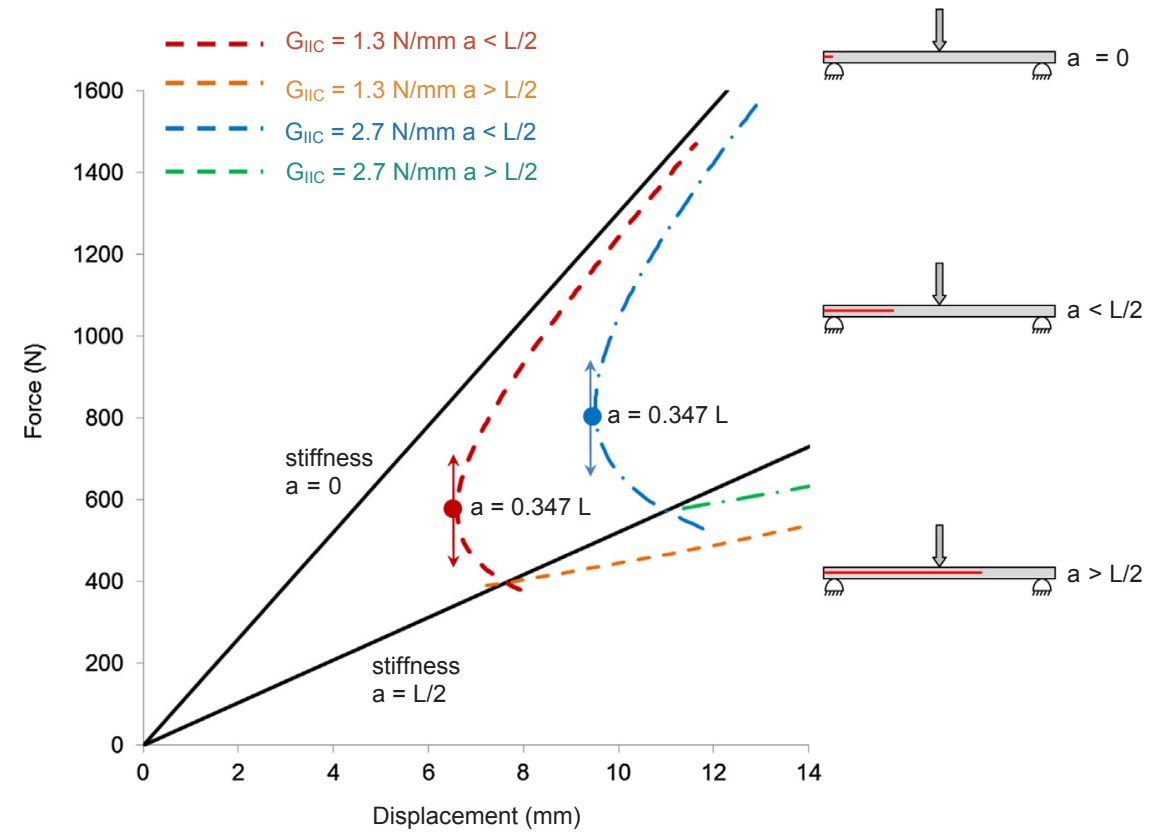

Fig. 10. Analytical curve of force versus displacement of the $E N F$ test for $\mathrm{G}_{\text {IIC }}=1.3 \mathrm{~N} / \mathrm{mm}$ and $\mathrm{G}_{\text {IIC }}=2.7 \mathrm{~N} / \mathrm{mm}$. 


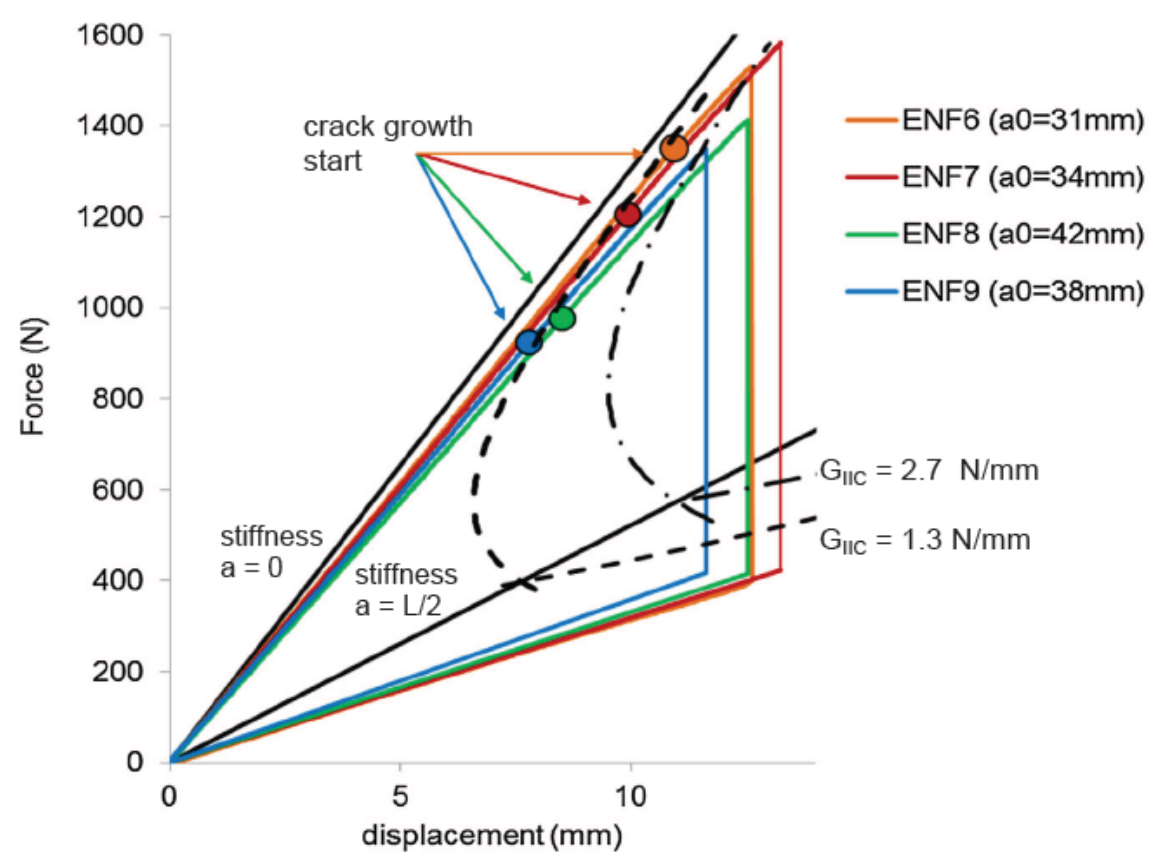

Fig. 11. Curves of force versus displacement of the ENF tests.

curve effect is often observed [10,14,22,27]. This is in particular the case for the tests in this study (Fig. 4).

In Fig. 11, the force versus displacement curves are plotted for the $\mathrm{ENF}_{6}$ to $\mathrm{ENF}_{9}$ samples. Specimens exhibit almost stable crack growth before reaching the maximum force and unstable crack growth beyond this point. The analytical curves of stable growth (Eq. (2)) for $\mathrm{G}_{\mathrm{IIC}}$ equal to 1.3 and $2.7 \mathrm{~N} / \mathrm{mm}$ are also plotted, together with the analytical stiffness where a is equal to 0 and $\mathrm{L} / 2$. These curves explain the crack growth of the different samples (more precise values of $\mathrm{G}_{\mathrm{IC}}$ will be determined afterwards):

- The crack growth starts similarly for the four samples where $\mathrm{G}_{\mathrm{IIC}}$ is equal to about $1.3 \mathrm{~N} / \mathrm{mm}$, regardless of the initial crack length

- Then the crack propagates slowly up to the maximum force. During this phase, $\mathrm{G}_{\mathrm{IIC}}$ increases to about $2.7 \mathrm{~N} / \mathrm{mm}$. This value may be even higher for the $\mathrm{ENF}_{8}$ test

- Afterwards, unstable crack growths are observed, and cracks stop at lengths higher than $\mathrm{L} / 2$. When the cracks stop, $\mathrm{G}_{\mathrm{IIC}}$ values may be lower than the initial $\mathrm{G}_{\mathrm{IIC}}=1.3 \mathrm{~N} / \mathrm{mm}$.

\subsection{Compliance calibration method}

In order to confirm the previous $\mathrm{G}_{\mathrm{IIC}}$ values, ENF tests were conducted and treated using the compliance calibration method [21 23]. It consists of doing a previous linear regression of experimental compliance, $C$, versus $\mathrm{a}^{3}$ to evaluate the slope of the curve,

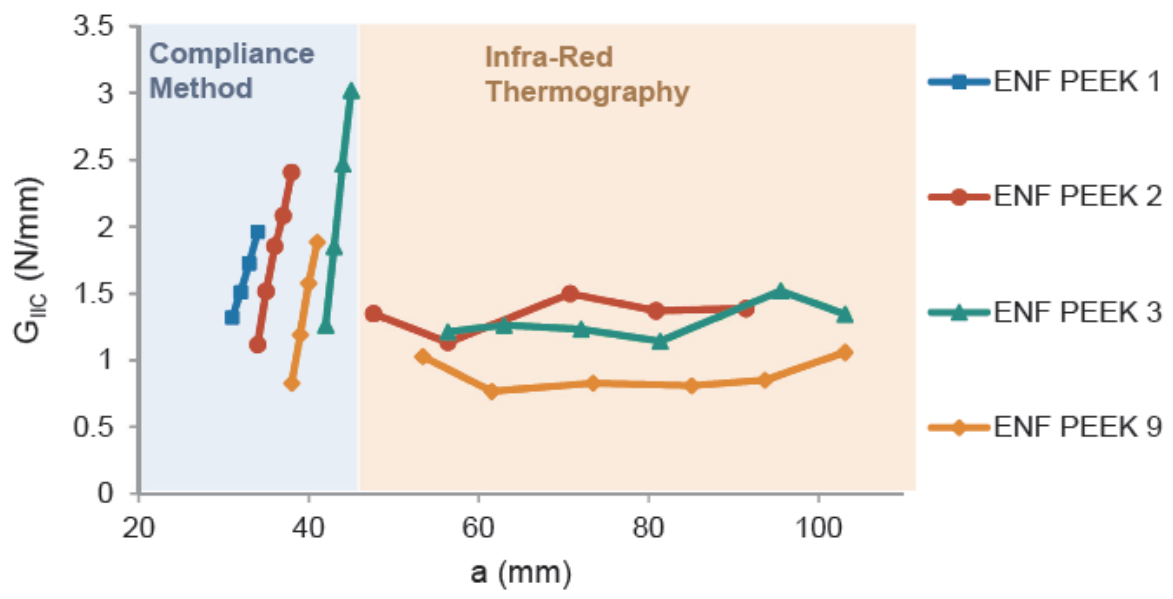

Fig. 12. Fracture toughness versus crack growth evolution of the ENF tests. 
$\mathrm{m}$, and the ERR is expressed by:

$$
G_{I I c}=\frac{3 m a^{2} F^{2}}{2 B} \text { with } C=C_{0}+m a^{3}
$$

Then fracture toughness can be obtained as it varies with crack length $a$. The fracture toughness determined via the compliance method confirmed the maximum value when crack growth starts, previously determined as $\mathrm{G}_{\mathrm{IIC}}=1.3 \mathrm{~N} / \mathrm{mm}$. Then the $\mathrm{R}$ curve, mentioned previously, was confirmed because fracture toughness increased from $0.61 .3 \mathrm{~N} / \mathrm{mm}$ to $1.43 \mathrm{~N} / \mathrm{mm}$ in a few millimeters of stable crack growth (Fig. 12). Since the compliance calibration method is only robust during stable propagation [21 23], this technique cannot be used after the point of maximum force (when unstable propagation begins). This is where infrared thermography proves useful because it can be applied for unstable propagation.

\subsection{Fracture toughness evaluation using infrared thermography}

Infra red thermography has been applied to fracture mechanics problems related to composite materials since the mid 1980s $[28,29]$. The concept of infrared thermography (IRT) is based on a thermo mechanical background. The full details can be found in $[27,3032]$. The principle of IRT is to use the heat diffusion equation to evaluate the intrinsic dissipation of the damaged material. Infrared thermography makes it possible to evaluate the left term of the heat diffusion equation using the spatial and temporal data of the film and thus obtain the right term from the intrinsic dissipation:

$$
\rho C \frac{d \theta}{d t}-\left(k_{l l} \frac{\partial^{2} \theta}{\partial l^{2}}+k_{t t} \frac{\partial^{2} \theta}{\partial t^{2}}+k_{z z} \frac{\partial^{2} \theta}{\partial z^{2}}\right)=\phi_{i n t}+s_{\text {the }}
$$

where $\rho$ is the mass density, $C$ is the specific heat capacity, $\theta=T-T_{0}$ is the temperature variation between the current state and the initial equilibrium state, $\mathrm{T}_{0}, \mathrm{k}_{\mathrm{ll}}\left(\mathrm{k}_{\mathrm{tt}}, \mathrm{k}_{\mathrm{zz}}\right)$ is the conductivity in $\mathrm{l}(\mathrm{t}, \mathrm{z})$ direction, $\phi_{\text {int }}$ is the intrinsic dissipation and $\mathrm{s}_{\text {the }}$ is the thermo mechanical coupling. The thermo mechanical coupling is negligible compared to intrinsic dissipation $\left(\mathrm{s}_{\text {the }} \ll \phi_{\text {int }}\right)[27,3236]$. Moreover the irreversible dissipation $\phi_{\text {irrev }}$, which is necessary to evaluate fracture toughness, can be separated into two parts; the intrinsic dissipation $\phi_{\text {int }}$ evaluated using IRT and the stored energy $\phi_{\text {stored: }}$

$$
\phi_{\text {irrev }}=\phi_{\text {int }}+\phi_{\text {stored }}
$$

In practice, the stored energy is very difficult to quantify and the Taylor Quinney coefficient [33] is needed. This coefficient denotes the ratio of energy dissipated as heat, the intrinsic dissipation, $\mathrm{dW}_{\mathrm{diss}}$, to irreversible energy, $\mathrm{dW}_{\mathrm{irrev}}$ :

$$
\beta=\frac{\int_{t_{A}}^{t_{A+d A}} \int_{\Omega_{\mathrm{fis}}} \phi_{\text {int }} d V \cdot d t}{\int_{t_{A}}^{t_{A}+d A} \int_{\Omega_{\text {fis }}} \phi_{\text {irrev }} d V \cdot d t} \approx \frac{d W_{\text {diss }}}{d W_{\text {irrev }}}
$$

More precisely, the Taylor Quinney coefficient is defined as the ratio of the integrals over time and space of the intrinsic dis sipation, $\mathrm{dW}_{\text {diss, }}$ and of the irreversible energy, $d W_{\text {irrev }}$, where $A$ is the crack area at time $t_{A}, A+d A$ is the crack area at time $t_{A+d A}$ and $\Omega_{\text {fis }}$ is the volume containing the crack [27,30 32]. The Taylor Quinney coefficient is between 0 and 1 and it is equal to 1 if all the dissipated energy is converted into heat. Then if this coefficient is known, it is possible to evaluate the critical ERR, $\mathrm{G}_{\mathrm{c}}$ :

$$
G_{c}=\frac{d W_{\text {irrev }}}{d A}=\frac{d W_{\text {diss }}}{\beta d A}
$$

The intrinsic dissipation $\phi_{\text {int }}$ can be assessed using IRT (left term of Eq. (5)) and temporal and spatial integration must be performed in order to calculate the dissipated energy $\mathrm{dW}_{\text {diss. }}$. The infrared thermography technique does not enable fracture modes (I, II or III) to be separated, but only assesses the total fracture toughness. An additional study is required to identify the contribution of different modes to $G_{c}$. In the case of the ENF test, the total energy release rate is equal to the shear fracture toughness $\left(G_{c}=G_{I I c}\right)$.

IRT enables the fracture toughness to be measured in a localized way, but $\beta$ must be known and this depends on damage mechanisms. Several studies demonstrate that the $\beta$ ratio depends on various parameters, such as the strain level, strain rate and the

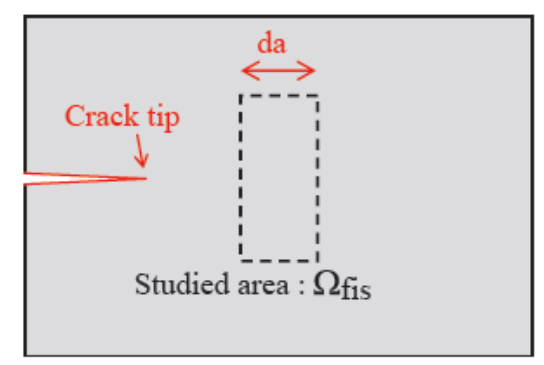

Time : ${ }^{\mathrm{A}}$

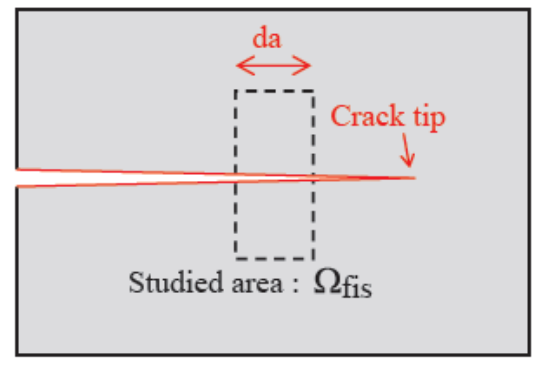

Time : $\mathrm{t} \mathrm{A}+\mathrm{dA}$

Fig. 13. Principle of fracture toughness evaluation using infra-red thermography. 
damage mechanisms involved [32,34,37 38]. In the literature, very little information is available on the values of $\beta$ for resins [27 32]. Li and Lambros [38] measured the ratio of dissipative work converted into heat for a polycarbonate material and they found that it varies from $100 \%$ for low strain to $50 \%$ for high strain. For metallic materials, some further studies exist in the literature. For example, Kapoor and Nemat Nasser [37] show that $\beta$ is close to 1 for a Ta $2.5 \%$ Bhalla et al. [39] measured values of $\beta$ between 0.5 and 1 depending on the strain for an annealed 302 stainless steel. With the same material, Zehnder et al. [40] studied cracks in a $0.8 \mathrm{~mm}$ plate for stable tearing growth. They showed that quantitative imaging of the crack tip temperature field using IRT can be used to resolve crack tip energy flux and to measure the energy release rate.

Moreover, the $\beta$ coefficient in composite materials depends on the damage mode [27,30 34]: $\beta$ value is close to 1 when damage consists of cracks, i.e. a brittle fracture mode and $\beta$ value is low when damage consists of resin "plasticity", i.e. a ductile fracture mode. This phenomenon may be linked to the fracture modes (Fig. 2) observed by Friedrich et al. [9 11]. If the fracture mode changes during crack growth, the $\beta$ coefficient can also change. It is likely that the $\beta$ value is close to 1 for unstable crack growth and $\beta$ values may be lower for stable crack growth. As it is difficult to accurately assess $\beta$, this study is based on the hypothesis that $\beta$ is equal to 1 . The fact that fast unstable propagation is present during these ENF tests endorses this hypothesis.

For unstable crack growth, the IRT method was adapted by choosing $t_{\mathrm{A}}$ just before the crack crossing the studied area and $\mathrm{t}_{\mathrm{A}+\mathrm{dA}}$ just after the crack crossed the studied area (Fig. 13). Then dA was directly the length of the studied area, multiplied by the width. In fact, the calculation was independent of the thickness, because dissipated energy, $\mathrm{dW}_{\text {diss, }}$, was also an integration over the volume, which was reduced to an integration over the surface, if $\mathrm{dA}$ is, at the same time, reduced to a length.

This method was used to calculate $\mathrm{G}_{\text {IIC }}$ (Eq. (8) with $\beta=1$ ) in several lines (n1 to n6 plotted in Fig. 14). These lines correspond to the volume $\Omega_{\text {fis }}$ and they represent thermal gauges. The position of the thermal gauges at the front of the specimen is fixed during the test. When the crack crosses the thermal gauge, temperature varies (similar to what is presented in Fig. 7 ) and $\mathrm{G}_{\text {IIC }}$ can be calculated by integrating the temperature variation over time and the gauge length. These gauges enabled $\mathrm{G}_{\text {IIC }}$ to be calculated with the crack in different positions in order to have an evolution of $\mathrm{G}_{\mathrm{IIC}}$ with the crack growth (Fig. 12). We can observe a uniform $\mathrm{G}_{\mathrm{IIC}}$ value for the whole duration of the unstable propagation. The values of $\mathrm{G}_{\mathrm{IIC}}$ are shown in Table 2 and they correspond to a time $t_{\mathrm{A}+\mathrm{dA}}=0.03 \mathrm{~s}$ (Fig. 14) because fracture toughness is uniform at this time. Mean values of fracture toughness during unstable propagation vary from $0.9 \mathrm{~N} / \mathrm{mm}$ to $1.5 \mathrm{~N} / \mathrm{mm}$. When brittle damage linked to unstable propagation takes place, fracture toughness decreases drastically ( $\sim 50 \%$ of the values obtained at maximum force).

These values are in line with those estimated by beam theory and the compliance method (Fig. 7). This significant correlation partly justifies the choice of $\beta=1$ and must be due to the brittle nature of the crack. As mentioned above, a high fracture toughness value is found for stable crack growth, and a low fracture toughness value is found for unstable crack growth.

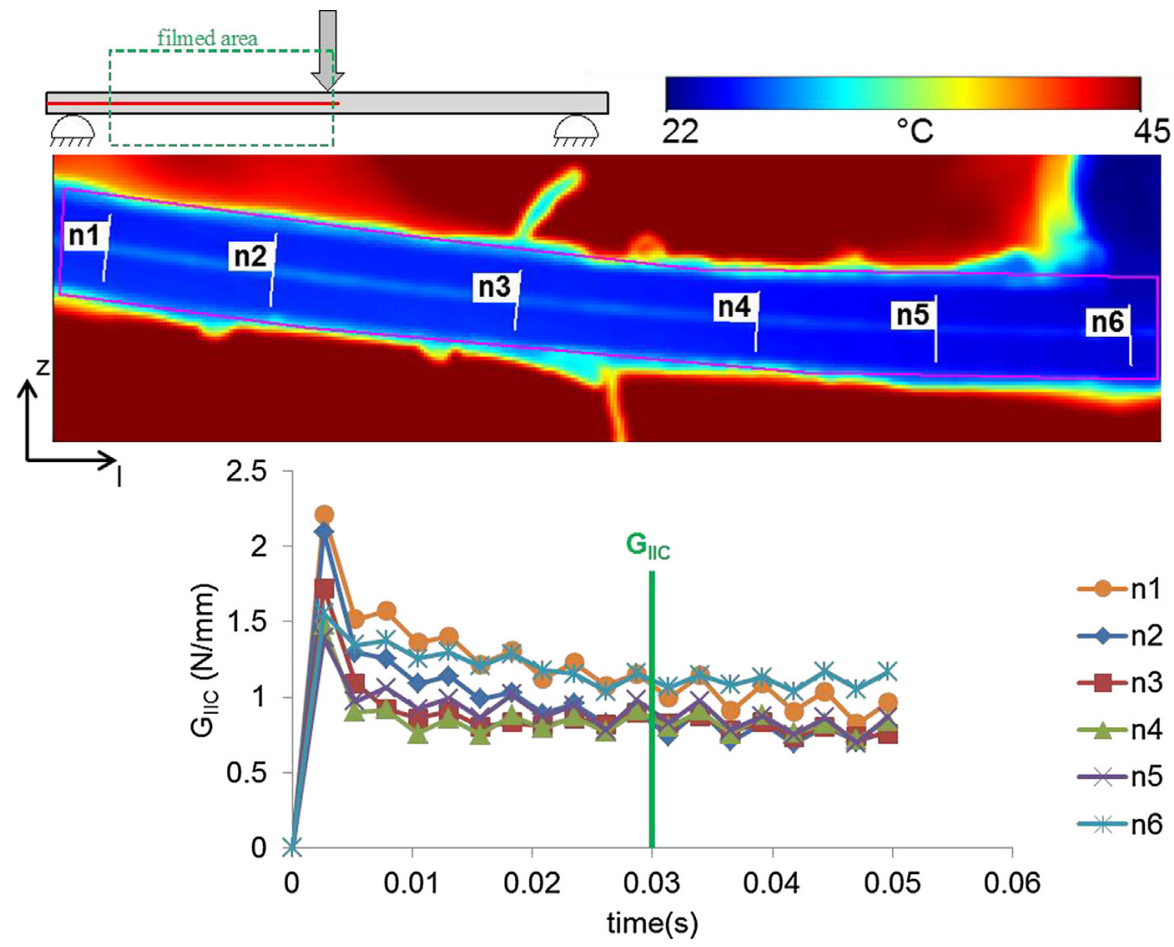

Fig. 14. Temperature field during $\mathrm{ENF}_{8}$ test and the thermal gauges used to calculate $\mathrm{G}_{\text {IIC }}$ via IRT technique. 
Table 2

Comparison of $\mathrm{G}_{\text {IIC }}$ calculated via compliance method and IRT technique for initial crack $\mathrm{a}_{0}$, crack at maximum force $\mathrm{a}_{\mathrm{Fmax}}$ and during unstable propagation a.

\begin{tabular}{|c|c|c|c|c|c|c|}
\hline & \multicolumn{4}{|c|}{ Compliance method } & \multicolumn{2}{|c|}{ IRT technique } \\
\hline & $\mathrm{a}_{0}(\mathrm{~mm})$ & $\mathrm{G}_{\mathrm{IIC}}(\mathrm{N} / \mathrm{mm})$ & $\mathrm{a}_{\mathrm{Fmax}}(\mathrm{mm})$ & $\mathrm{G}_{\mathrm{IIC}}(\mathrm{N} / \mathrm{mm})$ & a $(\mathrm{mm})$ & Average $\mathrm{G}_{\mathrm{IIC}}(\mathrm{N} / \mathrm{mm})$ \\
\hline $\mathrm{ENF}_{6}$ & 31 & 1.3 & 34 & 2.0 & - & - \\
\hline $\mathrm{ENF}_{7}$ & 34 & 1.1 & 38 & 2.4 & $47-100$ & 1.5 \\
\hline $\mathrm{ENF}_{8}$ & 42 & 1.3 & 45 & 3.0 & $56-103$ & 1.3 \\
\hline $\mathrm{ENF}_{9}$ & 38 & 0.8 & 41 & 1.9 & $53-103$ & 0.9 \\
\hline
\end{tabular}

\section{Conclusion}

An ENF test was used to study the effect of growth stability on mode II interlaminar fracture toughness of a carbon/PEEK composite. The instability of the ENF test was used to induce both stable (or slow) and unstable (or fast) crack growth with a static loading. Unstable propagation was filmed with an ultra high speed camera in order to determine crack growth velocity, varying from $807 \mathrm{~m} / \mathrm{s}$ to $962 \mathrm{~m} / \mathrm{s}$. Then two processes were used to evaluate fracture toughness: the standard compliance method and the Infra Red Thermography (IRT) technique.

The standard compliance method enabled $\mathrm{G}_{\text {IIC }}$ to be assessed using force and displacement imposed on the ENF sample, and the crack growth length was measured during the test $\left[\begin{array}{ll}21 & 23\end{array}\right]$. Initial fracture toughness varied from $\left.\left.0.6 \mathrm{~N} / \mathrm{mm}^{(\mathrm{ENF}}\right)_{9}\right)$ to $1.3 \mathrm{~N} / \mathrm{mm}$ $\left(\mathrm{ENF}_{6}\right.$ and $\left.\mathrm{ENF}_{8}\right)$. Afterwards, stable propagation took place until the point of maximum force, when $\mathrm{G}_{\text {IIC }}$ increased to a value

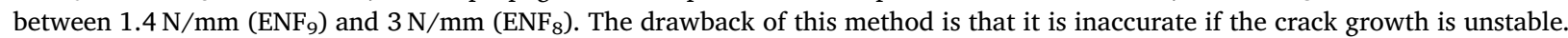

Then an Infra Red Thermography (IRT) process was applied. This technique enabled fracture toughness to be assessed using the heat energy dissipated by the crack growth [30 32]. This technique is very promising because it makes it possible to assess $\mathrm{G}_{\text {IIC }}$ in unclassical tests for which other techniques are not applicable. Nevertheless, in order to quantitatively evaluate crack growth dis sipated energy the Taylor Quinney coefficient [33] is needed. This coefficient represents the ratio of energy dissipated as heat to irreversible energy, and it can be difficult to assess [32 34,38]. This technique was used to estimate fracture toughness during ENF test with unstable propagation. From its maximum force peak value, $\mathrm{G}_{\mathrm{IIC}}$ decreased to a value comprised between $0.9 \mathrm{~N} / \mathrm{mm}\left(\mathrm{ENF}_{9}\right)$ and $1.5 \mathrm{~N} / \mathrm{mm}\left(\mathrm{ENF}_{7}\right)$.

This high variation in the fracture toughness with crack growth velocity is most likely due to the transition between a ductile fracture mode for low velocity (stable process) and a brittle fracture mode for high velocity (unstable propagation).

The complementarity between these two experimental techniques made it possible to determine carbon/PEEK G test with stable or unstable crack propagation. The results obtained using the infra red thermography technique show a significant correlation to $\mathrm{G}_{\text {IIC }}$ values calculated via the standard compliance method.

\section{Acknowledgement}

This work was supported by DGA and by Région Aquitaine. The authors wish to thank the "Ecole Nationale d'Ingénieur de Tarbes" for the loan of the infrared camera.

\section{References}

[1] Morton J, Godwin EW. Impact response of tough carbon fibre composites. Compos Struct 1989;13(1):1-19.

[2] Prevorsek DC, Chin HB, Bhatnagar A. Damage tolerance: design for structural integrity and penetration. Compos Struct 1993;23(2):137-48.

[3] De Baere I, Jacques S, Van Paepegem W, Degrieck J. Study of the mode I and II inter-laminar behavior of a carbon fabric reinforced TP. Polym Test 2012;31(2):322-32

[4] Davies P, Benzeggagh ML, De Charentenay FX. The delamination behavior of carbon fiber reinforced PPS. 32nd int SAMPE symposium. 1987. p. 134-46.

[5] Lachaud F, Lorrain B, Michel L, Barriol R. Experimental and numerical study of delamination caused by local buckling of TP and TS composites. Compos Sci Technol 1997;58:727-33.

[6] O'Brien K. Composite interlaminar shear fracture toughness GIIc: shear measurement or sheer myth. Technol Memorandum, NASA; 1997.

[7] Vieille B, Casado VM, Bouvet C. About the impact behavior of woven-ply carbon fiber-reinforced thermoplastic- and thermosetting-composites: a comparative study. Compos Struct 2013;101:9-21.

[8] Vieille B, Casado VM, Bouvet C. Influence of matrix toughness and ductility on the compression after impact behavior of woven-ply thermoplastic and thermosetting composites: a comparative study. Compos Struct 2014;110:207-18.

[9] Friedrich K, Walter R, Carlsson LA, Smiley AJ, Gillepsie JW. Mechanisms for rate effects on interlaminar fracture toughness of carbon/epoxy and carbon/peek composites. J Mater Sci 1989;24(9):3387-98.

[10] Smiley AJ, Pipes RB. Rate sensitivity of mode II interlaminar fracture toughness in graphite/epoxy and graphite/peek composite materials. Compos Sci Technol 1987;29:1-15.

[11] Gillepsie JW, Carlsson LA, Smiley AJ. Rate-dependent mode I interlaminar crack growth mechanisms in graphite/epoxy and graphite/peek. Compos Sci Technol 1987;28:1-15.

[12] Russell AJ, Street KN. The effect of matrix toughness on delamination: static and fatigue fracture under mode II shear loading of graphite fiber composites. Tough Compos 1987;ASTM STP 937:275-94.

[13] Rivallant S, Bouvet C, Hongkarnjanakul N. Failure analysis of CFRP laminates subjected to compression after impact: FE simulation using discrete interface elements. Compos Part A 2013;55:83-93.

[14] Prombut P, Michel L, Lachaud F, Barrau JJ. Delamination of multidirectional composite laminates at $0^{\circ} /$ Theta $^{\circ}$ ply interfaces. Eng Fract Mech 
2006;7(16):2427-42.

[15] Davies GAO, Zhang X. Impact damage prediction in carbon composite structures. Int J Imp Eng 1995;16:149-70.

[16] Hongkarnjanakul N, Bouvet C, Rivallant S. Validation of low velocity impact modelling on different stacking sequences of CFRP laminates and influence of fibre failure. Compos Struct 2013;106:549-59.

[17] Chai H. Interlaminar shear fracture of laminated composites. Int J Fract 1990;43:117-31.

[18] Blackman BRK, Dear JP, Kinloch AJ, MacGillivray H, Wang Y, Williams JG, et al. The failure of fibre composites and adhesively bonded fibre composites under high rates of test. Part III, J Mater Sci 1996;31:4467-77.

[19] Berger L, Cantwell WJ. Temperature and loading rate effects in the mode II interlaminar fracture behavior of carbon fiber reinforced PEEK. Polym Compos $2001 ; 22(2): 271-81$

[20] Beguelin P, Barbezat M, Kausch HH. Mechanical characterization of polymers and composites with a servohydraulic high-speed tensile tester. J Phys III 1991;1(12):1867-80.

[21] Allix O, Ladevèze P. Damage analysis of interlaminar fracture specimens. Compos Struct 1995;31:61-74.

[22] Davies P. Protocols for interlaminar fracture testing of composites. ESIS-Polymers \& Composites Task Group, IFREMER, Centre de Brest; 1993.

[23] Pereira AB, Morais AB, Marques AT, Castro PT. Mode II interlaminar fracture of carbon/epoxy multidirectional laminates. Compos Sci Technol 2004;64:1653-9.

[24] Stroh AN. A theory of the fracture of metals. Adv Phys 1957;6(24):418-65.

[25] Rayleigh JWSB. The theory of sound vol. 2. Macmillan; 1896.

[26] Bluhm JL. Fracture arrest, fracture: an advanced treatise. New York: Academic Press; 1969.

[27] Soumahoro Z. Etude du couplage thermomécanique dans la propagation dynamique de fissure. Thesis of Ecole Polytechnique; 2005.

[28] Dulieu-Barton JM, Stanley P. Development and applications of thermoelastic stress analysis. J Strain Anal 1998;33(2):93-104.

[29] Stanley P, Chan WK. The application of thermoelastic stress analysis techniques to composite materials. J Strain Anal 1998;23(3):137-43.

[30] Lisle T, Bouvet C, Pastor ML, Margueres P, Prieto Corral R. Damage analysis and fracture toughness evaluation in a thin woven composite laminate under static tension using infrared thermography. Compos Part A 2013;53:75-87.

[31] Lisle T, Bouvet C, Hongkarnjanakul N, Pastor ML, Rivallant S, Margueres P. Measure of fracture toughness of compressive fiber failure in composite structures using infrared thermography. Compos Sci Technol 2015;112:22-33.

[32] Lisle T, Bouvet C, Pastor ML, Rouault T, Margueres P. Damage of woven composite under tensile and shear stress using infrared thermography and micrographic cuts. J Mater Sci 2015;50:6154-70.

[33] Taylor GI, Quinney H. The latent energy remaining in a metal after cold working. R Soc A: Math Phys Eng Sci 1934.

[34] Rittel D. On the conversion of plastic work to heat during high strain rate deformation of glassy polymers. Mech Mater 1999;31(2):131-9.

[35] Weichert R, Schonert K. On the temperature rise at the tip of a fast running crack. J Mech Phys Sol 1974;22(2):127-33.

[36] Weichert R, Schonert K. Heat generation at the tip of a moving crack. J Mech Phys Sol 1978;26(3):151-61.

[37] Kapoor R, Nemat-Nasser S. Determination of temperature rise during high strain rate deformation. Mech Mater 1998;27(1):1-12.

[38] Li ZH, Lambros J. Strain rate effects on the thermomechanical behavior of polymers. Int J Sol Struct 2001;38(20):3549-62.

[39] Bhalla K, Zehnder A, Han X. Thermomechanics of slow stable crack growth: closing the loop between experiments and computational modeling. Engng Fract Mech 2003;70(17):2439-58.

[40] Zehnder A, Babinsky E, Palmer T. Hybrid method for determining the fraction of plastic work converted to heat. Exp Mech 1998;38(4):295-302.

[41] HexTow carbon fiber data sheet. Hexcel; 2014.

[42] GoodFellow PEEK resin datasheet. GoodFellow; 2014.

[43] Lemarchand F. Etude de l'apparition des contraintes résiduelles dans le procédé d'empilement par soudage et consolidation en continu de composites thermoplastiques. Thesis of Ecole Nationale des Arts et Métiers; 2010. 